\title{
Changes in Glucose Metabolism after Adrenalectomy or Treatment with a Mineralocorticoid Receptor Antagonist for Primary Aldosteronism
}

\author{
Yu-Fang Lin ${ }^{1}$, Kang-Yung Peng ${ }^{2}$, Chia-Hui Chang ${ }^{3}$, Ya-Hui Hu${ }^{3}$, Vin-Cent Wu ${ }^{1}$, Shiu-Dong Chung ${ }^{4,5}$, \\ Taiwan Primary Aldosteronism Investigation (TAIPAI) Study Group
}

${ }^{1}$ Division of Nephrology, Department of Internal Medicine, National Taiwan University Hospital; ${ }^{2}$ Department of Internal Medicine, National Taiwan University Hospital, Taipei; ${ }^{3}$ Division of Endocrinology and Metabolism, Department of Internal Medicine, Taipei Tzu Chi Hospital, The Buddhist Medical Foundation; ${ }^{4}$ Division of Urology, Department of Surgery, Far-Eastern Memorial Hospital, New Taipei; ${ }^{5}$ Graduate Program in Biomedical Informatics, College of Informatics, Yuan-Ze University, Chung-Li, Taiwan

Background: Data on the effects of excess aldosterone on glucose metabolism are inconsistent. This study compared the changes in glucose metabolism in patients with primary aldosteronism (PA) after adrenalectomy or treatment with a mineralocorticoid receptor antagonist (MRA).

Methods: Overall, 241 patients were enrolled; 153 underwent adrenalectomy and 88 received an MRA. Fasting glucose, homeostatic model assessment of insulin resistance (HOMA-IR), and homeostatic model assessment of $\beta$-cell function (HOMA- $\beta$ ) were compared between the treatment groups after 1 year. Plasma aldosterone concentration (PAC) and factors determining HOMA-IR and PAC were evaluated.

Results: No baseline differences were observed between the groups. Fasting insulin, HOMA-IR, and HOMA- $\beta$ increased in both groups and there were no significant differences in fasting glucose following treatment. Multiple regression analysis showed associations between PAC and HOMA-IR $(\beta=0.172, P=0.017)$ after treatment. Treatment with spironolactone was the only risk factor associated with PAC $>30 \mathrm{ng} / \mathrm{dL}$ (odds ratio, 5.2; 95\% confidence interval [CI], 2.7 to $10 ; P<0.001$ ) and conferred a 2.48-fold risk of insulin resistance after 1 year compared with surgery $(95 \% \mathrm{CI}, 1.3$ to $4.8 ; P=0.007)$.

Conclusion: Spironolactone treatment might increase insulin resistance in patients with PA. This strengthened the current recommendation that adrenalectomy is the preferred strategy for patient with positive lateralization test. Achieving a post-treatment PAC of $<30 \mathrm{ng} / \mathrm{dL}$ for improved insulin sensitivity may be appropriate.

Keywords: Hyperaldosteronism; Adrenalectomy; Spironolactone; Insulin resistance

Received: 6 August 2020, Revised: 11 September 2020,

Accepted: 23 September 2020

Corresponding author: Shiu-Dong Chung

Division of Urology, Department of Surgery, Far-Eastern Memorial Hospital,

No.21, Sec. 2, Nanya S. Rd., Banciao Dist., New Taipei City, Taiwan

Tel: +886-972652560, Fax: +886-2-89667000, E-mail: chungshiudong@gmail.com
Copyright $\odot 2020$ Korean Endocrine Society

This is an Open Access article distributed under the terms of the Creative Commons Attribution Non-Commercial License (https://creativecommons.org/ licenses/by-nc/4.0/) which permits unrestricted non-commercial use, distribution, and reproduction in any medium, provided the original work is properly cited. 


\section{INTRODUCTION}

The relationship between abnormal glucose metabolism and primary aldosteronism (PA) has been explored in previous studies. More than 50 years ago, Conn [1] observed an increased incidence of impaired glucose tolerance in patients with PA. Conn [1] originally implicated hypokalemia and impaired insulin secretion in the pathogenesis of hyperaldosteronism-induced type 2 diabetes mellitus; however, treatment for hypokalemia only partially corrected the insulin secretory defect.

Several studies and organizations have found an unprecedented increase in the prevalence of diabetes worldwide; the estimated number of adults with diabetes has increased to over 380 million in 2011 to 2012 [2]. The Expert Committee on the Diagnosis and Classification of Diabetes Mellitus has always considered PA to be the endocrine cause of diabetes [3]. In addition to the effects of aldosterone itself, an epidemiologic study demonstrated that glucose intolerance is common among patients with hypertension [4]. However, Fallo et al. [5] demonstrated that patients with PA had a significantly higher prevalence of metabolic syndrome (as defined by the Adult Treatment Panel III criteria) than those with essential hypertension. In fact, serum aldosterone levels were independently associated with the development of the metabolic syndrome in the general population included in the Framingham Offspring Study [6].

Reports suggest that pancreatic cell function is impaired in patients with PA, in addition to insulin sensitivity [7]. Data on changes in glucose metabolism after specific treatments for PA are inconsistent, and there is no consensus regarding the most suitable treatment choice for PA in terms of glucose metabolism. Furthermore, the most appropriate method of glucose metabolism evaluation after PA treatment remains to be determined. In this study, we sought to investigate the change in insulin resistance after specific treatment in patients with PA. Apart from reinterpreting the influence of insulin resistance by aldosterone, our aim was to determine the most efficient treatment to obtain improved glucose metabolism in patients with PA, and evaluate glucose metabolism after treatment.

\section{METHODS}

\section{Ethical consideration}

The work was conducted in accordance with the Declaration of Helsinki, the Human Tissue Act and was approved by our Institutional Ethical Committee (National Taiwan University Hospital: 200611031R). All patients provided written informed consent.

\section{Study population}

The study population included patients referred to the Taiwan Primary Aldosteronism Investigation (TAIPAI) study group, which comprised two medical centers, three affiliated hospitals, and two regional hospitals in different cities of Taiwan. Individuals diagnosed with PA between 2013 and 2017 were enrolled. The diagnosis of PA was confirmed by the saline-loading and captopril tests, with subsequent subtype identification. All interfering antihypertensive medications were discontinued for at least 21 days before the confirmatory tests and adrenal venous sampling procedures were conducted. Doxazosin and/or diltiazem were administered to control exceedingly high blood pressure, as appropriate [8]. Among patients with hypertension, confirmation of the PA diagnosis and subtype studies, including adrenal venous sampling and ${ }^{131}$ I-iodocholesterol scintigraphy with single-photon emission computed tomography imaging, was performed according to the standard protocol of the TAIPAI study and the aldosteronism consensus of Taiwan [8].

Patients diagnosed with diabetes mellitus according to the American Diabetes Association criteria [9], renal insufficiency (estimated glomerular filtration rate $<30 \mathrm{~mL} / \mathrm{min} / 1.73 \mathrm{~m}^{2}$ ), Cushing syndrome, autonomous cortisol secretion, and patients lost to follow-up were excluded. As an indicator of hypercortisolism, autonomous cortisol secretion was defined as a 24-hour urine free-cortisol in excess of thrice the upper normal limit, random serum cortisol $>25 \mu \mathrm{g} / \mathrm{dL}$, or cortisol levels $>1.8 \mu \mathrm{g} /$ $\mathrm{dL}$ following the $1 \mathrm{mg}$-dexamethasone-suppression-test [10]. Adrenalectomy was performed by experienced surgeons, using the lateral trans-peritoneal laparoscopic approach. Patients who did not meet surgical standards or who were unwilling to undergo operation received mineralocorticoid receptor antagonist (MRA): spironolactone. Data on the body mass index (BMI), systolic blood pressure (SBP) and diastolic blood pressure, serum potassium, serum creatinine, plasma aldosterone concentration (PAC), plasma renin activity (PRA), fasting glucose, fasting insulin, homeostatic model assessment of insulin resistance (HOMA-IR), and homeostatic model assessment of $\beta$-cell function (HOMA- $\beta$ ) were obtained at baseline and at 1 year after treatment. We scheduled follow-up appointments according to each patient's preferences to minimize the ratio of loss to follow-up. Study design, exclusion criteria, and allocation of patients are presented in Fig. 1.

\section{Laboratory measurements and calculation of indices}

Plasma aldosterone was measured by method of radioimmunoassay using a commercial kit (Cisbio, Codolet, France). The 


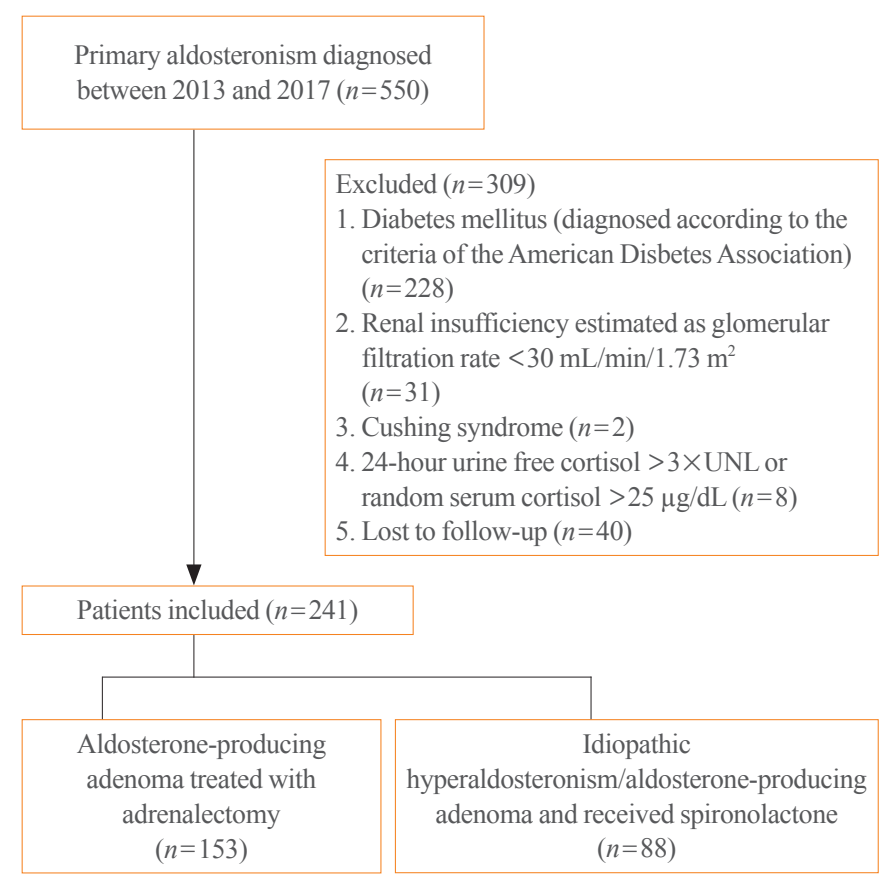

Fig. 1. Flow chart of study design, exclusion criteria, and allocation of patients. UNL, upper normal limit.

lowest detectable concentration of aldosterone was $7 \mathrm{pg} / \mathrm{mL}$ and the normal range of aldosterone was 97 to $626 \mathrm{pg} / \mathrm{mL}$ (9.7 to $62.6 \mathrm{ng} / \mathrm{dL}$ ) in the upright position. PRA was identified as the generation of angiotensin I by in vitro analysis using a commercially available radioimmunoassay kit (Beckman Coulter, Immunotech, Prague, Czech Republic). The normal range of PRA was 0.7 to $3.3 \mathrm{ng} \mathrm{mL} / \mathrm{hr}$ in the upright position.

The following indices were utilized in this study: HOMA-IR (fasting plasma glucose $\times$ fasting insulin) $/ 405$, HOMA- $\beta$ (360× fasting insulin/ [fasting plasma glucose-63] \%); the unit of mass of glucose was mg/dL. According to a population-based prospective cohort study with a high negative predictive value of 92.6\% [11], the optimal HOMA-IR cutoff for insulin resistance was at 2.0 .

\section{Statistical analysis}

The data are presented as mean \pm standard deviation or as median (interquartile range) percentile. The independent $t$ test was used to describe the baseline differences between the two treatment groups; the paired $t$ test was used to compare clinical parameters before and after treatment. In all statistical analyses, the statistical significance level was set at $P<0.05$. Logistic regression analysis was performed to identify determinants of HOMA-IR at baseline and after treatment. To determine the significant different variables, we put those which were considered as predictors in previous studies or those having $P$ value(s) lower than 0.1 in the univariate logistic regression analysis, into multivariate logistic regression analysis. The SPSS Statistics version 22.0 software package (IBM Corp., Armonk, NY, USA) was used for all analyses. To evaluate the effects of aldosterone in individual patients and predict the outcomes, a generalized additive model (with spline), incorporating the subject-specific (longitudinal) random effects, was plotted after adjusting for other clinical parameters, including age, sex, serum potassium, serum creatinine, and SBP. This approach permitted adjustments for possible nonlinear effects of continuous variables; the value at which the log odd equaled zero was considered the optimal cutoff point [12].

\section{RESULTS}

\section{Baseline demographic and clinical characteristics of study participants}

A total of 241 patients with PA (mean age, 50.6 years; sex, men $46.5 \%$, women $53.5 \%$ ) were eligible for the final analysis. Among them, 153 and 88 underwent adrenalectomy and received spironolactone, respectively. As shown in Table 1, there were no differences in glucose metabolism between the two groups at baseline (fasting glucose: $P=0.106$; fasting insulin: $P=0.653$; HOMA-IR: $P=0.849$; HOMA- $\beta$ : $P=0.231$ ). Patients who underwent adrenalectomy were younger than those who received spironolactone $(P=0.028)$. In patients who underwent adrenalectomy, the baseline serum potassium and PAC levels were lower $(P<0.001)$ and higher $(P=0.004)$, respectively.

\section{Changes in clinical characteristics of study participants following treatment}

No changes in fasting glucose levels were observed at 1 year after treatment in both groups. Fasting insulin, HOMA-IR, and HOMA- $\beta$ levels increased in both groups after treatment. The above four variables were similar between the two groups. PAC was the only variable that differed significantly $(P<0.001)$; its level increased following treatment with spironolactone, but decreased after adrenalectomy (Table 2).

Hypertension and hypokalemia improved significantly after both treatments, while the serum creatinine levels increased in both groups $(P<0.001)$. The BMI increased in patients who underwent adrenalectomy $(P=0.032)$, but not in those who received spironolactone $(P=0.327)$. 
Table 1. Comparison of Demographic and Clinical Characteristics of Study Participants before Targeted Therapies

\begin{tabular}{lccc}
\hline Characteristic & Adrenalectomy $(n=153)$ & Spironolactone $(n=88)$ & $P$ value \\
\hline Age, $\mathrm{yr}$ & $49.4 \pm 10.9$ & $52.6 \pm 12.5$ & $0.045^{\mathrm{a}}$ \\
Sex, male/female & $66 / 87$ & $42 / 46$ & 0.915 \\
BMI, $\mathrm{kg} / \mathrm{m}^{2}$ & $24.86(22.5-27.11)$ & $24.88(23.02-27.42)$ & 0.175 \\
SBP, $\mathrm{mm} \mathrm{Hg}$ & $152(139-167)$ & $148(136-161)$ & 0.714 \\
DBP, $\mathrm{mm} \mathrm{Hg}$ & $90(83-100)$ & $89(82-98)$ & $0.000^{\mathrm{a}}$ \\
Serum potassium, $\mathrm{mEq} / \mathrm{L}$ & $3.5(3.1-4)$ & $3.8(3.6-4.03)$ & 0.534 \\
Serum creatinine, $\mathrm{mg} / \mathrm{dL}$ & $0.8(0.7-1)$ & $0.8(0.7-1)$ & $0.001^{\mathrm{a}}$ \\
PAC, ng/dL & $48.14(34.34-76.23)$ & $43.5(31.7-54.82)$ & 0.215 \\
PRA, ng/mL/hr & $0.19(0.07-0.51)$ & $0.45(0.14-0.78)$ & $0.006^{\mathrm{a}}$ \\
ARR & $252.96(75.32-782.86)$ & $105.74(44-291.84)$ & 0.110 \\
Plasma glucose, $\mathrm{mg} / \mathrm{dL}$ & $92(85-100)$ & $94(87-102)$ & 0.469 \\
Insulin, $\mu \mathrm{U} / \mathrm{mL}$ & $6.42(3-12)$ & $8.19(4.66-11.15)$ & 0.559 \\
HOMA-IR & $1.51(0.67-2.74)$ & $1.81(1.03-2.93)$ & 0.151 \\
HOMA- $\beta$ & $0.83(0.43-1.51)$ & $0.87(0.5-1.3)$ & \\
\hline
\end{tabular}

Values are expressed as mean \pm standard deviation or median (interquartile range).

BMI, body mass index; SBP, systolic blood pressure; DBP, diastolic blood pressure; PAC, plasma aldosterone concentration; PRA, plasma renin activation; ARR, aldosterone renin ratio; HOMA-IR, homeostasis model assessment-insulin resistance; HOMA- $\beta$, homeostasis model assessment of $\beta$-cell function.

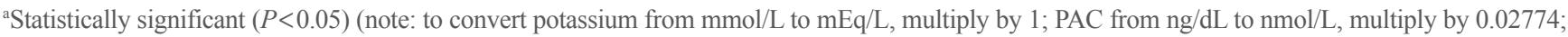
PRA from $\mathrm{ng} / \mathrm{mL} / \mathrm{hr}$ to $\mathrm{ng} / \mathrm{L} / \mathrm{sec}$, multiply by 0.2778$)$.

\section{The relation between PAC and HOMA-IR after treatment}

Multiple regression analysis demonstrated that post-treatment PAC was independently correlated with HOMA-IR at 1 year after treatment $(\beta=0.172, P=0.017$ ) (Table 3 ). The PAC after treatment was plotted against the log odds of increased HOMA-IR, using a cutoff value of $\mathrm{PAC}=30 \mathrm{ng} / \mathrm{dL}(\log [\mathrm{PAC}=30 \mathrm{ng} / \mathrm{dL}]=$ 1.47) (Fig. 2). Treatment with spironolactone was the only risk factor associated with PAC $>30 \mathrm{ng} / \mathrm{dL}$, with an odds ratio of 5.2 $(P<0.001)$ (Table 4).

As shown in Table 2, 62.5\% of patients who received spironolactone had HOMA-IR values $>2$, whereas $47 \%$ of patients who underwent surgery had HOMA-IR values $>2$ (significant difference, $P=0.023$ ). As demonstrated in Table 4 , treatment with spironolactone conferred a 2.48 -fold risk of insulin resistance after 1 year compared with surgery $(P=0.007)$.

\section{DISCUSSION}

In this study, post-treatment PAC correlated positively with insulin resistance, independent of the BMI. The positive correlation between PAC and insulin resistance among patients with PA is consistent with previous findings, which suggested a significantly higher prevalence of metabolic syndrome in PA [5]. More- over, we found that post-treatment PAC levels of $<30 \mathrm{ng} / \mathrm{mL}$ were more common after adrenalectomy than after treatment with spironolactone, and were associated with improved insulin sensitivity at 1-year follow-up.

Glucose homeostasis involves a fine balance between tissue sensitivity to insulin and insulin secretion [13]. Analyses of prospective data from Pima Indians indicated that insulin resistance and insulin secretory dysfunction are independent predictors of deteriorating glucose tolerance [14]. Therefore, our discussion cut in from these two aspects.

\section{The impact of adrenalectomy}

The findings of our study are similar to those of a clinical retrospective study from Japan, which demonstrated an increase in insulin resistance in patients with aldosterone-producing adenomas, 1 year after adrenalectomy [15]. The insulinogenic index and HOMA-IR significantly increased after surgery [15].

The increase in insulin resistance may have resulted from the increase of BMI after adrenalectomy, which negated the metabolic benefit $(P=0.032)$ (Table 2$)$; the post-treatment BMI was found to have a significant association with increased HOMAIR $(P<0.001)$ (Table 3). 
Table 2. Serial Time Change in the Clinical Characteristics of Study Participants before and after Targeted Therapy

\begin{tabular}{|c|c|c|c|c|c|c|c|}
\hline \multirow{2}{*}{ Characteristic } & \multicolumn{3}{|c|}{ Adrenalectomy $(n=153)$} & \multicolumn{3}{|c|}{ Spironolactone $(n=88)$} & \multirow{2}{*}{$\begin{array}{c}\text { Follow-up data } \\
P \text { value }\end{array}$} \\
\hline & Baseline & Follow-up & $P$ value ${ }^{\mathrm{a}}$ & Baseline & Follow-up & $P$ value ${ }^{\mathrm{b}}$ & \\
\hline BMI, $\mathrm{kg} / \mathrm{m}^{2}$ & $\begin{array}{c}24.86 \\
(22.5-27.11)\end{array}$ & $\begin{array}{c}25.1 \\
(22.89-27.66)\end{array}$ & $0.032^{\mathrm{d}}$ & $\begin{array}{c}24.88 \\
(23.02-27.42)\end{array}$ & $\begin{array}{c}25.03 \\
(22.75-27.46)\end{array}$ & 0.327 & 0.411 \\
\hline SBP, mm Hg & $\begin{array}{c}152 \\
(139-167)\end{array}$ & $\begin{array}{c}136 \\
(126-148)\end{array}$ & $<0.001^{\mathrm{d}}$ & $\begin{array}{c}148 \\
(136-161)\end{array}$ & $\begin{array}{c}137 \\
(127-151)\end{array}$ & $<0.001^{\mathrm{d}}$ & 0.393 \\
\hline DBP, $\mathrm{mm} \mathrm{Hg}$ & $\begin{array}{c}90 \\
(83-100)\end{array}$ & $\begin{array}{c}84 \\
(78-90)\end{array}$ & $<0.001^{\mathrm{d}}$ & $\begin{array}{c}89 \\
(82-98)\end{array}$ & $\begin{array}{c}84 \\
(79-92)\end{array}$ & $<0.001^{\mathrm{d}}$ & 0.542 \\
\hline Serum potassium, $\mathrm{mEq} / \mathrm{L}$ & $\begin{array}{c}3.5 \\
(3.1-4)\end{array}$ & $\begin{array}{c}4.3 \\
(4.1-4.5)\end{array}$ & $<0.001^{\mathrm{d}}$ & $\begin{array}{c}3.8 \\
(3.6-4.03)\end{array}$ & $\begin{array}{c}4.2 \\
(4-4.5)\end{array}$ & $<0.001^{\mathrm{d}}$ & 0.089 \\
\hline Serum creatinine, $\mathrm{mg} / \mathrm{dL}$ & $\begin{array}{c}0.8 \\
(0.7-1)\end{array}$ & $\begin{array}{c}0.9 \\
(0.8-1.2)\end{array}$ & $<0.001^{\mathrm{d}}$ & $\begin{array}{c}0.8 \\
(0.7-1)\end{array}$ & $\begin{array}{c}0.9 \\
(0.8-1.01)\end{array}$ & $<0.001^{\mathrm{d}}$ & 0.123 \\
\hline $\mathrm{PAC}, \mathrm{ng} / \mathrm{dL}$ & $\begin{array}{c}48.14 \\
(34.34-76.23)\end{array}$ & $\begin{array}{c}28.6 \\
(19.9-40.11)\end{array}$ & $<0.001^{\mathrm{d}}$ & $\begin{array}{c}43.5 \\
(31.7-54.82)\end{array}$ & $\begin{array}{c}54.3 \\
(38.5-77.22)\end{array}$ & $0.004^{d}$ & $<0.001^{\mathrm{d}}$ \\
\hline PRA, ng/mL/hr & $\begin{array}{c}0.19 \\
(0.07-0.51)\end{array}$ & $\begin{array}{c}1.5 \\
(0.59-3.66)\end{array}$ & $0.002^{\mathrm{d}}$ & $\begin{array}{c}0.45 \\
(0.14-0.78)\end{array}$ & $\begin{array}{c}1.61 \\
(0.49-3.98)\end{array}$ & $<0.001^{\mathrm{d}}$ & 0.676 \\
\hline ARR & $\begin{array}{c}252.96 \\
(75.32-782.86)\end{array}$ & $\begin{array}{c}18.95 \\
(9-45.85)\end{array}$ & $<0.001^{\mathrm{d}}$ & $\begin{array}{c}105.74 \\
(44-291.84)\end{array}$ & $\begin{array}{c}35.79 \\
(13.89-115.12)\end{array}$ & $0.022^{\mathrm{d}}$ & 0.529 \\
\hline Plasma glucose, mg/dL & $\begin{array}{c}92 \\
(85-100)\end{array}$ & $\begin{array}{c}93 \\
(86-99)\end{array}$ & 0.053 & $\begin{array}{c}94 \\
(87-102)\end{array}$ & $\begin{array}{c}94 \\
(88-1000)\end{array}$ & 0.785 & 0.926 \\
\hline Insulin, $\mu \mathrm{U} / \mathrm{mL}$ & $\begin{array}{c}6.42 \\
(3-12)\end{array}$ & $\begin{array}{c}9.06 \\
(4.58-15.4)\end{array}$ & $0.003^{\mathrm{d}}$ & $\begin{array}{c}8.19 \\
(4.66-11.15)\end{array}$ & $\begin{array}{c}9.58 \\
(5.27-15.63)\end{array}$ & $0.005^{\mathrm{d}}$ & 0.811 \\
\hline HOMA-IR & $\begin{array}{c}1.51 \\
(0.67-2.74)\end{array}$ & $\begin{array}{c}2.17 \\
(1.12-3.56)\end{array}$ & $0.007^{\mathrm{d}}$ & $\begin{array}{c}1.81 \\
(1.03-2.93)\end{array}$ & $\begin{array}{c}2.08 \\
(1.19-3.84)\end{array}$ & $0.006^{\mathrm{d}}$ & 0.610 \\
\hline НОМА- $\beta$ & $\begin{array}{c}0.83 \\
(0.43-1.51)\end{array}$ & $\begin{array}{c}1.07 \\
(0.6-1.8)\end{array}$ & $0.030^{\mathrm{d}}$ & $\begin{array}{c}0.87 \\
(0.5-1.3)\end{array}$ & $\begin{array}{c}1.14 \\
(0.58-1.64)\end{array}$ & $0.011^{\mathrm{d}}$ & 0.870 \\
\hline HOMA-IR > 2.0 after treatment & $\begin{array}{c}63 \\
(41.2)\end{array}$ & $\begin{array}{c}70 \\
(47)\end{array}$ & 0.346 & $\begin{array}{c}40 \\
(45.5)\end{array}$ & $\begin{array}{c}55 \\
(62.5)\end{array}$ & 0.228 & $0.023^{\mathrm{d}}$ \\
\hline
\end{tabular}

Values are expressed as median (interquartile range) or number (\%).

BMI, body mass index; SBP, systolic blood pressure; DBP, diastolic blood pressure; PAC, plasma aldosterone concentration; PRA, plasma renin activation; ARR, aldosterone renin ratio; HOMA-IR, homeostasis model assessment of insulin resistance; HOMA- $\beta$, homeostasis model assessment of $\beta$-cell function.

${ }^{\mathrm{a}}$ The comparison between the clinical characteristics before and after adrenalectomy; ${ }^{\mathrm{b}}$ The comparison between the clinical characteristics before and after spironolactone; ${ }^{\mathrm{C}}$ The comparison between the clinical characteristics after adrenalectomy and spironolactone; ${ }^{\mathrm{d}}$ Statistically significant $(P<0.05)($ note: to convert potassium from $\mathrm{mmol} / \mathrm{L}$ to $\mathrm{mEq} / \mathrm{L}$, multiply by 1 ; PAC from $\mathrm{ng} / \mathrm{dL}$ to $\mathrm{nmol} / \mathrm{L}$, multiply by $0.02774 ; \mathrm{PRA}$ from ng/mL/hr to ng/L/sec, $\mathrm{multiply}$ by 0.2778$)$.

\section{The impact of spironolactone}

As depicted in Table 2, PAC significantly increased after spironolactone treatment. A compensatory increase in PAC is common after treatment with MRA [16]; this impairs the coupling of glucose sensing or stimulus-response with subsequent insulin secretion [14]. In an in vitro study, the MRAs spironolactone, eplerenone, and RU-28318 did not prevent the inhibition of insulin secretion by aldosterone, suggesting that its impact on insulin secretion was mediated via a mineralocorticoid receptorindependent mechanism. This may be related to the non-genomic effects of aldosterone that are not blocked by MRAs [14,17].
We found that patients administered with spironolactone were 2.45 and 5 times more likely to develop insulin resistance and have post-treatment PAC levels of $>30 \mathrm{ng} / \mathrm{dL}$ after treatment, respectively, than those undergoing surgery. Moreover, posttreatment PAC levels were positively correlated with HOMAIR (Table 3, Fig. 2). This finding concurs with that of previous studies [18], which found that HOMA-IR independently correlated with plasma aldosterone.

Additionally, owing to its non-genomic action, aldosterone increases collagen synthesis or fibrosis to a certain extent in patients with PA; this damages insulin-producing or insulin-sensi- 
Table 3. Multiple Regression Analysis of Variables Determining Homeostasis Model Assessment of Insulin Resistance after Treatment

\begin{tabular}{lcc}
\hline Variable & $\beta$ & $P$ value \\
\hline Age, $\mathrm{yr}$ & & 0.736 \\
SBP, $\mathrm{mm} \mathrm{Hg}$ & 0.160 & $0.008^{\mathrm{a}}$ \\
BMI after treatment, $\mathrm{kg} / \mathrm{m}^{2}$ & 0.382 & $<0.001^{\mathrm{a}}$ \\
Serum creatinine after treatment, $\mathrm{mg} / \mathrm{dL}$ & & 0.522 \\
\hline $\begin{array}{l}\text { Serum potassium after treatment, } \mathrm{mEq} / \mathrm{L} \\
\text { Log (PAC after treatment) }\end{array}$ & 0.172 & 0.420 \\
$\begin{array}{l}\text { The amplitude of the change of PAC after } \\
\text { treatment (percentage) }\end{array}$ & & $0.017^{\mathrm{a}}$ \\
\end{tabular}

Values are expressed as standardized regression coefficients $(\beta)$ and $P$ value.

SBP, systolic blood pressure; BMI, body mass index; PAC, plasma aldosterone concentration.

${ }^{\text {a }}$ Statistically significant $(P<0.05)$ (note: to convert potassium from $\mathrm{mmol} / \mathrm{L}$ to $\mathrm{mEq} / \mathrm{L}$, multiply by 1 ; PAC from $\mathrm{ng} / \mathrm{dL}$ to $\mathrm{nmol} / \mathrm{L}$, multiply by 0.02774 ; PRA from $\mathrm{ng} / \mathrm{mL} / \mathrm{hr}$ to $\mathrm{ng} / \mathrm{L} / \mathrm{sec}$, multiply by 0.2778 ).

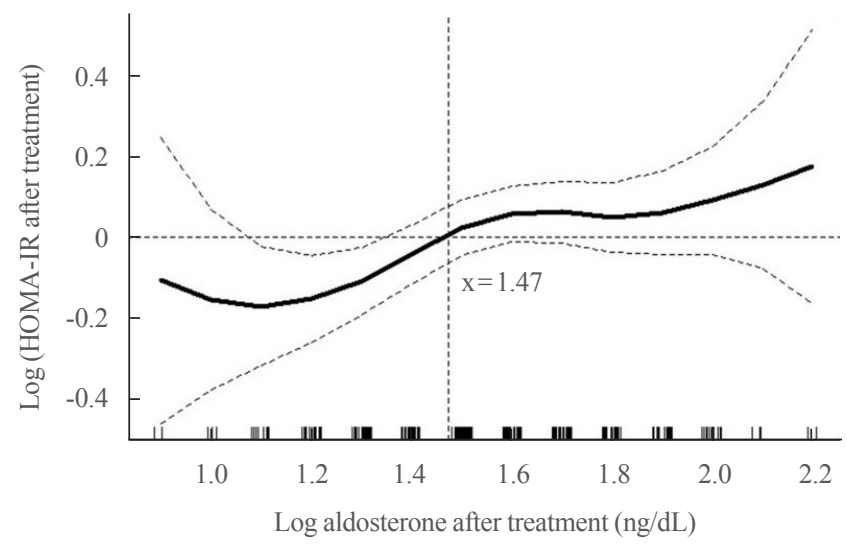

Fig. 2. Association between the aldosterone levels and homeostasis model assessment of insulin resistance (HOMA-IR). Generalized additive model showing a positive nonlinear relationship between $\log$ (HOMA-IR after treatment) against log (aldosterone after treatment) after adjusting for age, sex, serum potassium, serum creatinine, and systolic blood pressure. Log (plasma aldosterone concentration $=30[\mu \mathrm{g} / \mathrm{L}])=1.47$ was an independent factor predicting increased HOMA-IR after treatment.

tive tissues, resulting in clinical alterations in insulin release or sensitivity [19].

\section{The effect of treatment on glucose metabolism in PA}

An epidemiologic study has shown that glucose intolerance is common among patients with hypertension [4]. In a random population sample comprising more than 2,000 individuals, a
Table 4. Correlation of Treatment Modalities with PAC and HOMA-IR

\begin{tabular}{lccc}
\hline Variable & Odds ratio & $95 \%$ CI & $P$ value \\
\hline $\begin{array}{l}\text { Post-treatment HOMA-IR }>2 \\
\text { Treatment methods }\end{array}$ & 2.482 & $1.285-4.793$ & $0.007^{\mathrm{a}}$ \\
$\quad$ (MRA vs. adrenalectomy) & & & \\
$\begin{array}{c}\text { Post-treatment PAC }>30 \mathrm{ng} / \mathrm{dL} \\
\text { Treatment methods } \\
\quad \text { (MRA vs. adrenalectomy) }\end{array}$ & 5.225 & $2.728-10.005$ & $<0.001^{\mathrm{a}}$ \\
\hline
\end{tabular}

PAC, plasma aldosterone concentration; HOMA-IR, homeostasis model assessment of insulin resistance; CI, confidence interval; MRA, mineralocorticoid receptor antagonist.

${ }^{a}$ Statistically significant $(P<0.05)$ (note: to convert potassium from $\mathrm{mmol} / \mathrm{L}$ to $\mathrm{mEq} / \mathrm{L}$, multiply by $1 ;$ PAC from $\mathrm{ng} / \mathrm{dL}$ to $\mathrm{nmol} / \mathrm{L}$, multiply by 0.02774 ; PRA from $\mathrm{ng} / \mathrm{mL} / \mathrm{hr}$ to $\mathrm{ng} / \mathrm{L} / \mathrm{sex}$, multiply by 0.2778 ).

highly significant $(P<0.001)$ association was observed between hypertension and glucose intolerance, independent of the potentially confounding effects of age, sex, obesity, and anti-hypertensive medications. The rate ratios for hypertension were 1.48 (range, 1.18 to 1.87 ) in abnormal glucose tolerance and 2.26 (range, 1.69 to 2.84) in diabetes compared with normal tolerance [20]. Hypertension is an insulin-resistant condition, and it has been associated with an increased incidence of diabetes [21,22]. A case-control study from Germany found a higher prevalence of diabetes mellitus in patients with PA than in those with hypertension [23]. In theory, glucose metabolism should improve with the control of hypertension in individuals with PA.

A previous study revealed a reduction in the incidence of new-onset diabetes mellitus in patients with PA who had undergone adrenalectomy; in contrast, patients treated with MRAs had an increased risk after a mean of 5.2 years of follow-up [24]. The post-treatment duration of follow-up in the present study was 1 year; this may not have been sufficient to detect significant differences in fasting glucose resulting from the treatments. However, disparities were observed in insulin resistance between the two specific treatments.

A German group has found that more than $70 \%$ of patients with PA have autonomous cortisol secretion [25]. These patients had higher 2-hour glucose levels during the oral glucose tolerance test and a higher prevalence of type 2 diabetes mellitus than the control group. In theory, adrenalectomy could radically solve the adverse impact of cortisol, whereas MRA could not. Moreover, similar to our findings, this study group found a favorable impact of adrenalectomy on glucose metabolism [24]. Based on the body of evidence presented, we infer that in the long-term, 
adrenalectomy improves insulin sensitivity relative to the aldosterone levels in patients with PA. Our study contributes to the accumulating evidence suggesting that adrenalectomy may reduce the subsequent risk of new-onset diabetes mellitus.

According to the Primary Aldosteronism Surgical Outcome study, which is an international project to develop consensus criteria for outcomes and follow-up of adrenalectomy for unilateral PA, complete and partial biochemical success is defined by PAC levels of $<5$ and 5-10 ng/dL, respectively from a saline loading test [26]. We inferred that the post-treatment PAC levels of $<30 \mathrm{ng} / \mathrm{dL}$ (Fig. 2) were associated with improved insulin sensitivity irrespective of adrenalectomy or spironolactone. However, further studies focused on achieving a post-treatment PAC of $<30 \mathrm{ng} / \mathrm{dL}$ are needed.

\section{Limitations of the study}

This study has certain limitations. First, $\beta$-cell function and insulin resistance were evaluated using HOMA- $\beta$ and HOMA-IR, respectively, instead of the gold standards, namely, the hyperglycemic and euglycemic clamps [27]. HOMA-IR may underestimate insulin resistance in patients with PA. However, the estimates of insulin resistance obtained by HOMA are correlated with that obtained using the euglycemic clamp [28]. Second, the post-treatment follow-up period was only 1 year, which may have been inadequate for detecting a statistically significant difference in fasting glucose levels and HOMA- IR between the two treatment procedures. However, the proportion of HOMAIR $>2$ after treatment was greater in those receiving spironolactone than among those who underwent adrenalectomy.

To our knowledge, the present study used the largest sample size among those that investigated changes in glucose metabolism after treatment for PA. Post-treatment PAC positively correlated with insulin resistance, independent of the BMI. Although HOMA-IR or fasting glucose were not significantly different between the two groups, treatment with spironolactone was a risk factor for high PAC compared to surgery, and predicted insulin resistance at follow-up after 1 year. This strengthened the current recommendation that adrenalectomy is the preferred strategy for patient with positive lateralization test. Further studies focused on achieving a post-treatment PAC of $<30$ $\mathrm{ng} / \mathrm{dL}$ for improved insulin sensitivity, are warranted.

\section{CONFLICTS OF INTEREST}

No potential conflict of interest relevant to this article was reported.

\section{ACKNOWLEDGMENTS}

The manuscript was revised by a native English speaker (Eric Chueh, B.A, MBA program [in progress], Case Western Reserve University, Cleveland, OH, USA). This study was supported by the Taiwan National Science Council (101-2314-B002-085-MY3, 102-2314-B-002-140-MY2, 104-2314-B-002125-MY3, 106-2314-B-002 -166 -MY3,107-2314-B-002-026MY3), National Health Research Institutes (PH-102-SP-09), National Taiwan University Hospital (106-FTN20, 106-P02, UN106-014, 106-S3582, 105-P05, VN105-04, 105-S3061, 107S3809, 107-T02), and Ministry of Science and Technology (MOST) of the Republic of China (Taiwan) (grant number, MOST 106-2321-B-182-002).

Membership of the TAIPAI Study Group as following: TaiShuan Lai, Vin-Cent Wu, Shao-Yu Yang, Kao-Lang Liu, ChinChen Chang, Bo-Chiag Lee, Shuo-Meng Wang, Kuo-How Huang, Po-Chih Lin, Yen-Hung Lin, Lian-Yu Lin, Shih-Cheng Liao, Ruoh-Fang Yen, Ching-Chu Lu (National Taiwan University Hospital, Taipei, Taiwan); Chieh-Kai Chan (NTUH HsinChu branch); Leay-Kiaw Er, Ya-Hui Hu, Chia-Hui Chang, CheHsiung Wu, Yao-Chou Tsaiv (Taipei Tzu Chi Hospital, Buddhist Tzu Chi Medical Foundation, Taipei, Taiwan); Shih-Chieh Jeff Chueh (Cleveland Clinic Institute of Urology and Kidneys); Chen-Hsun Ho (Taipei Medical University-Shuang Ho Hospital, Ministry of Health and Welfare); Wei-Chieh Huang (New Taipei City Hospital); Ying-Ying Chen (MacKay Memorial Hospital); Kwan-Dun Wu (National Taiwan University Hospital, Taipei, Taiwan NTUH, Director of Coordinating Center).

\section{AUTHOR CONTRIBUTIONS}

Conception or design: V.C.W., S.D.C. Acquisition, analysis, or interpretation of data: Y.F.L., K.Y.P. Drafting the work or revising: C.H.C., Y.H.H., V.C.W. Final approval of the manuscript: Y.F.L., K.Y.P., C.H.C., Y.H.H., V.C.W., S.D.C.

\section{ORCID}

Yu-Fang Lin https://orcid.org/0000-0002-9681-6471

Shiu-Dong Chung https://orcid.org/0000-0002-1817-6106

\section{REFERENCES}

1. Conn JW. Hypertension, the potassium ion and impaired carbohydrate tolerance. N Engl J Med 1965;273:1135-43. 
2. Menke A, Casagrande S, Geiss L, Cowie CC. Prevalence of and trends in diabetes among adults in the United States, 1988-2012. JAMA 2015;314:1021-9.

3. Expert Committee on the Diagnosis and Classification of Diabetes Mellitus. Report of the expert committee on the diagnosis and classification of diabetes mellitus. Diabetes Care 2003;26 Suppl 1:S5-20.

4. Kannel WB, Wilson PW, Zhang TJ. The epidemiology of impaired glucose tolerance and hypertension. Am Heart J 1991;121(4 Pt 2):1268-73.

5. Fallo F, Veglio F, Bertello C, Sonino N, Della Mea P, Ermani M, et al. Prevalence and characteristics of the metabolic syndrome in primary aldosteronism. J Clin Endocrinol Metab 2006;91:454-9.

6. Ingelsson E, Pencina MJ, Tofler GH, Benjamin EJ, Lanier $\mathrm{KJ}$, Jacques PF, et al. Multimarker approach to evaluate the incidence of the metabolic syndrome and longitudinal changes in metabolic risk factors: the Framingham Offspring Study. Circulation 2007;116:984-92.

7. Chen W, Li F, He C, Zhu Y, Tan W. Elevated prevalence of abnormal glucose metabolism in patients with primary aldosteronism: a meta-analysis. Ir J Med Sci 2014;183:283-91.

8. Wu VC, Hu YH, Er LK, Yen RF, Chang CH, Chang YL, et al. Case detection and diagnosis of primary aldosteronism: the consensus of Taiwan Society of Aldosteronism. J Formos Med Assoc 2017;116:993-1005.

9. American Diabetes Association. Diagnosis and classification of diabetes mellitus. Diabetes Care 2010;33 Suppl 1 (Suppl 1):S62-9.

10. Ohno Y, Sone M, Inagaki N, Takeda Y, Kurihara I, Tsuiki M, et al. Latent autonomous cortisol secretion from apparently nonfunctioning adrenal tumor in nonlateralized hyperaldosteronism. J Clin Endocrinol Metab 2019;104:4382-9.

11. Lee CH, Shih AZ, Woo YC, Fong CH, Leung OY, Janus E, et al. Optimal cut-offs of homeostasis model assessment of insulin resistance (HOMA-IR) to identify dysglycemia and type 2 diabetes mellitus: a 15-year prospective study in Chinese. PLoS One 2016;11:e0163424.

12. Hin LY, Lau TK, Rogers MS, Chang AM. Dichotomization of continuous measurements using generalized additive modelling: application in predicting intrapartum caesarean delivery. Stat Med 1999;18:1101-10.

13. Ferrannini E. Insulin resistance versus insulin deficiency in non-insulin-dependent diabetes mellitus: problems and prospects. Endocr Rev 1998;19:477-90.

14. Weyer C, Bogardus C, Mott DM, Pratley RE. The natural history of insulin secretory dysfunction and insulin resistance in the pathogenesis of type 2 diabetes mellitus. J Clin Invest 1999;104:787-94.

15. Tsurutani Y, Sugisawa C, Ishida A, Inoue K, Saito J, Omura $\mathrm{M}$, et al. Aldosterone excess may inhibit insulin secretion: a comparative study on glucose metabolism pre- and post-adrenalectomy in patients with primary aldosteronism. Endocr J 2017;64:339-46.

16. Luther JM, Gainer JV, Murphey LJ, Yu C, Vaughan DE, Morrow JD, et al. Angiotensin II induces interleukin-6 in humans through a mineralocorticoid receptor-dependent mechanism. Hypertension 2006;48:1050-7.

17. Wada T, Ohshima S, Fujisawa E, Koya D, Tsuneki H, Sasaoka T. Aldosterone inhibits insulin-induced glucose uptake by degradation of insulin receptor substrate (IRS) 1 and IRS2 via a reactive oxygen species-mediated pathway in 3T3-L1 adipocytes. Endocrinology 2009;150:1662-9.

18. Colussi G, Catena C, Lapenna R, Nadalini E, Chiuch A, Sechi LA. Insulin resistance and hyperinsulinemia are related to plasma aldosterone levels in hypertensive patients. Diabetes Care 2007;30:2349-54.

19. Giacchetti G, Sechi LA, Rilli S, Carey RM. The renin-angiotensin-aldosterone system, glucose metabolism and diabetes. Trends Endocrinol Metab 2005;16:120-6.

20. Modan M, Halkin H, Almog S, Lusky A, Eshkol A, Shefi M, et al. Hyperinsulinemia: a link between hypertension obesity and glucose intolerance. J Clin Invest 1985;75:809-17.

21. Ferrannini E, Buzzigoli G, Bonadonna R, Giorico MA, Oleggini M, Graziadei L, et al. Insulin resistance in essential hypertension. N Engl J Med 1987;317:350-7.

22. Shen DC, Shieh SM, Fuh MM, Wu DA, Chen YD, Reaven GM. Resistance to insulin-stimulated-glucose uptake in patients with hypertension. J Clin Endocrinol Metab 1988;66: 580-3.

23. Reincke M, Meisinger C, Holle R, Quinkler M, Hahner S, Beuschlein $\mathrm{F}$, et al. Is primary aldosteronism associated with diabetes mellitus?: results of the German Conn's Registry. Horm Metab Res 2010;42:435-9.

24. Wu VC, Chueh SJ, Chen L, Chang CH, Hu YH, Lin YH, et al. Risk of new-onset diabetes mellitus in primary aldosteronism: a population study over 5 years. J Hypertens 2017; 35:1698-708.

25. Gerards J, Heinrich DA, Adolf C, Meisinger C, Rathmann $\mathrm{W}$, Sturm L, et al. Impaired glucose metabolism in primary aldosteronism is associated with cortisol cosecretion. J Clin Endocrinol Metab 2019;104:3192-202. 
26. Williams TA, Lenders JW, Mulatero P, Burrello J, Rottenkolber M, Adolf C, et al. Outcomes after adrenalectomy for unilateral primary aldosteronism: an international consensus on outcome measures and analysis of remission rates in an international cohort. Lancet Diabetes Endocrinol 2017;5: 689-99.

27. DeFronzo RA, Tobin JD, Andres R. Glucose clamp tech- nique: a method for quantifying insulin secretion and resistance. Am J Physiol 1979;237:E214-23.

28. Matthews DR, Hosker JP, Rudenski AS, Naylor BA, Treacher DF, Turner RC. Homeostasis model assessment: insulin resistance and beta-cell function from fasting plasma glucose and insulin concentrations in man. Diabetologia $1985 ; 28: 412-9$. 